\title{
DEBERES VOCACIONALES DE LOS PASTORES
}

DOI: https://doi.org/10.52039/seminarios.v62i218.109

ALIAKSANDR YASHEUSKI*

Todos somos muy conscientes de nuestros deberes vocacionales como pastores, pero quizá sea útil recordar lo que ya es sabido y se nos pide, para interiorizarlo y confirmarnos en nuestra misión. Quisiera fijarme sobre todo en los obispos, en cuanto responsables de la pastoral vocacional, y seguidamente en sus sacerdotes.

\section{EL OBISPO PASTOR DE LAS VOCACIONES}

La imagen bíblica de Cristo, Buen Pastor, que conoce a sus ovejas, las guía hacia verdes pastos, vigila a las que están en su redil y se preocupa por las que faltan, nos recuerda el deber de confirmar en la fe a los hermanos por las distintas sendas (Jn 10,16). La animación de la pastoral centrada en las vocaciones sacerdotales compete al obispo, que es llamado a suscitar y coordinar la colaboración de toda la Iglesia que le ha sido confiada ${ }^{1}$.

De esta afirmación deriva que la primera preocupación del obispo debe ser la de integrar plenamente la dimensión vocacional en la vida de la Iglesia, puesto que de ella nacen y maduran las vocaciones sacerdotales. Mirando a su grey como a una familia, el obispo es un padre que la sigue y se preocupa con su experiencia de garantizar un número suficiente de pastores y ministros. Para conseguir un número adecuado de vocaciones al ministerio sacerdotal hay que «instruir a todos los fieles sobre la importancia de su ministerio ${ }^{2}$, indispensable para el servicio necesario de edificar al Pueblo de Dios. Con el fin de llevar a cabo el deber de pastor, el obispo es evidente que no está solo y sus colaboradores más directos son los sacerdotes, los religiosos, los laicos, sobre todo los padres, los maestros, los movimientos y las asociaciones de fieles ${ }^{3}$.

* Aliaksandr Yasheuski es obispo auxiliar de Minsk-Milohelev (Bielorrusia).

1. Cf. Juan Pablo II, Pastores dabo vobis, 41.

2. Directorio para el ministerio pastoral de los obispos, 91.

3. Cf. Ratio fundamentalis institutionis sacerdotalis, 8. 
Todos han de hacer la parte que les corresponde, pero es obvio que difícilmente lo harán si el obispo no realiza al mismo tiempo la suya. De esto todos estamos convencidos, porque la comunidad cristiana, que hoy a menudo se siente perpleja o resignada respecto de las vocaciones, espera del obispo ideas claras y principalmente ejemplo de vida, estímulo y sostén, que brotan de una real paternidad pastoral. El servicio pastoral del obispo y la vocación de los creyentes en Cristo constituyen la estructura dialógica de la comunidad eclesial: el obispo es un llamado que a su vez llama. Así es para todo creyente: cada cristiano es un ser salvado que a su vez se convierte en irradiación de salvación para los otros.

Entre los sacerdotes que colaboran con el obispo están los párrocos, que guían las distintas comunidades. Junto a los párrocos, el resto de los presbíteros están llamados a acompañar espiritualmente a los jóvenes, junto con sus padres, para ofrecer una propuesta de vida cristiana completa, para cumplir la voluntad de Dios, incluso si esto significa servir al Señor en el altar ${ }^{4}$. Toda la comunidad cristiana tiene que crear un clima idóneo en el que los jóvenes viven para ser ayudados a vivir como cristianos a fondo.

La pastoral vocacional, en este sentido, no es un área aparte de la pastoral, ni siquiera representa un aspecto aislado, sino que es una dimensión que implica los fundamentos de la vida cristiana. Por esto, cabe decir que la familia cristiana constituye el primer seminario y la parroquia el segundo, sin olvidar las escuelas y las asociaciones que cultivan a sus alumnos para hacer que descubran la llamada de Dios en la vida y el modo de acogerla con generosidad $^{5}$. Precisamente el ministerio sacerdotal del obispo estimula al Pueblo de Dios para que tome conciencia de su llamada y de su identidad originaria. Con el fin de que esto suceda, ayuda a cada bautizado a dar su segunda respuesta: no sólo una respuesta a la Iglesia por una pertenencia recibida en el día del propio bautismo, sino en la Iglesia, por una pertenencia responsable y coherente. $Y$ todo según el misterioso don del Espíritu, que está siempre en la raíz del proyecto de Dios.

\section{a) El obispo, signo de una misión para la comunión}

En la comunidad eclesial, el ministerio del obispo se configura sobre todo como signo de una misión para la comunión y de una comunión para la misión. Por el sacramento del Orden, recibido en su plenitud, el obispo es y obra in persona Christi, en cuanto signo sacramental de Cristo Pastor. Desde esta figura, el obispo se convierte en icono de Cristo Pastor, misionero del Padre, servidor del proyecto de salvación. El horizonte en el que se coloca el

4. Cf. Directorio para el ministerio pastoral de los obispos, 91.

5. Concilio Vaticano II, Optatam totius, 2. 
servicio episcopal es la comunidad eclesial, pero no encerrada en sí misma, sino abierta al Reino en un mundo sin fronteras. No está el pueblo de los bautizados al servicio del ministerio episcopal, sino al contrario. El ministerio episcopal es para el Pueblo de Dios, ejerciendo sus funciones: enseñar, santificar y gobernar. El objetivo del ministerio episcopal es la comunión. El obispo es servidor de la misión de Cristo para la comunión del Pueblo de Dios y para la comunión a la que está llamada la humanidad entera.

\section{b) El obispo, signo de una comunión para la misión}

Además de ser signo de una misión para la comunión, el obispo está llamado a ser signo de una comunión para la misión. Para desarrollar tal misión no está solo, como ya mencionábamos. «Todos los presbíteros, sean diocesanos o religiosos, participan y ejercen con el obispo el único sacerdocio de Cristo; por consiguiente, quedan constituidos en asiduos cooperadores del orden episcopal ${ }^{6}$. El ministerio del obispo es ministerio de comunión, participado por los presbíteros que son sus cooperadores en el servicio de la comunidad. Obispos y presbíteros están conjuntamente comprometidos en una misión que se expresa en diversos niveles. En primer lugar, la comunidad, porque sobre todo la celebración de la presencia de Cristo en la eucaristía fundamenta y hace crecer en la comunión. En segundo lugar, las personas, para que cada uno se sienta vivamente partícipe del misterio de Dios y de la Iglesia. Y en tercer lugar el mundo, que va más allá de los límites de la Iglesia particular y se convierte en apertura y pasión misionera ${ }^{7}$. El obispo está llamado en primera persona a regir la comunidad, pero sobre todo a hacer que llegue a ser manifestación del misterio del Dios trinitario, a través de la diversidad de dones y ministerios. Las vocaciones son expresión de una fe adulta, capaz de respuestas responsables y coherentes con la iniciativa del Espíritu. En tal sentido el obispo es animador de toda llamada.

\section{c) El obispo, primer anunciador de las vocaciones al ministerio ordenado}

Dentro de la sucesión apostólica, el obispo se convierte en el primer anunciador de las vocaciones, y de manera especial de las vocaciones al ministerio ordenado. En efecto, es deber del pastor cuidar de forma específica a los futuros pastores. En este quehacer de sensibilización y discernimiento, también respecto de la vida consagrada, el obispo ocupa un papel de primordial, que no puede limitarse solo a exhortaciones paternales y a expresar principios generales.

6. Concilio Vaticano II, Christus Dominus, 28.

7. Cf. Concilio Vaticano II, Presbyterorum ordinis, 10. 
En su intervención en el I Congreso internacional para las vocaciones de especial consagración, san Juan XXIII dijo: «El problema de las vocaciones eclesiásticas y religiosas es cotidiana preocupación del Papa, es súplica de su oración, aspiración ardiente de su alma» ${ }^{8}$. Pienso que cada obispo puede hacer suyas estas palabras. El Concilio Vaticano II expresa muy claramente el papel del obispo como primer animador y suscitador de vocaciones. De ello habla el decreto Christus Dominus, que pide activar con la santidad los dos factores fundamentales de toda vocación: el modelo y la comunidad; a su vez, el decreto Optatam totius señala como deber de los obispos «impulsar a su grey a fomentar las vocaciones y procurar la estrecha unión de todos los esfuerzos y trabajos», llegando como padres «a ayudar, sin escatimar sacrificio alguno», a los llamados (OT 2).

\section{d) Los medios útiles para cumplir el deber vocacional}

El medio más importante para el crecimiento de las vocaciones es la oración. El Señor mismo nos lo ha dicho: «La mies es abundante, pero son pocos los operarios. Rogar, pues, al Dueño de la mies que envíe operarios a su mies» (Lc 10, 2).

La oración es un instrumento en manos de todos los componentes de la comunidad cristiana. No está en manos del reclutador hallar y llevar al altar a los futuros presbíteros con medios técnicos, incluso los más modernos y aparentemente eficientes. La oración está al alcance de todos, también de los obispos, de los sacerdotes y de los laicos, y no hay que descuidarla, sino valorarla con auténtica confianza y perseverar siempre. Siendo la oración la primera pastoral vocacional, hay que promoverla con especial insistencia y organización en la pastoral. No tendría que faltar en ninguna misa la intención de orar por las vocaciones de especial consagración.

En esta línea se proponen numerosas iniciativas vocacionales, que se adoptan en muchas diócesis, por ejemplo: el primer jueves de cada mes y la adoración eucarística mensual; las vigilias de oración y diversas experiencias fuertes de espiritualidad con jóvenes; los encuentros diocesanos con las familias, los educadores, los catequistas; la implicación de los jóvenes en iniciativas de servicio y voluntariado. Una oportunidad especialmente adecuada es la Jornada mundial de oración por las vocaciones, que en cada Iglesia particular de la que el obispo es pastor, viene a ser la meta, el punto de salida y de comprobación en el camino de la diócesis. El obispo, precisamente en esta especial celebración, puede explicitar su servicio de primer animador de la pastoral vocacional animando en cada área de la pastoral a preparar

8. Intervención en el I Congresso Internazionale per le Vocazioni di speciale consacrazione, Roma 16 de diciembre de 1961. 
la Jornada con una serie de iniciativas y a vivir un momento fuerte, unitario de oración de todas las vocaciones y por todas las vocaciones. Además de la oración conviene que el obispo sea el primero en dar ejemplo de santidad, de caridad, de humildad y de sencillez de vida, ayudando así «a avanzar por el camino de la santidad a sus sacerdotes, religiosos y laicos, según la vocación peculiar de cada uno» ${ }^{9}$.

Si la Palabra de Dios la siembra el obispo a manos llenas, será una semilla puesta no solo en el campo de la Iglesia, sino también en el corazón de cada uno, porque por sí misma la llamada del Verbo se desarrolla en un ambiente en el que la Palabra de Dios resuena y actúa. De ahí deriva la importancia fundamental para toda comunidad cristiana de ser suscitadora de vocaciones, de ser lugar de resonancia de la Palabras de Dios ${ }^{10}$.

Incluso el obispo más activo y emprendedor tiene el peligro de correr en vano si no constituye un Centro diocesano para la animación vocacional de la Iglesia particular. Se trata de un lugar de comunión, de animación y de promoción vocacional. Un organismo de comunión en el que las diversas categorías de vocaciones presentes en la Iglesia particular experimentan la unidad de la misión, la alegría y la fatiga de trabajar juntos por las vocaciones; un organismo de servicio e instrumento pastoral para que toda la Iglesia particular tenga conciencia de ser llamada ${ }^{11}$.

A través del Centro diocesano para la pastoral vocacional, el obispo, del cual es el primer y el último responsable, puede proponer itinerarios diversos en clave vocacional. Está bien que él mismo, al comienzo del año pastoral, cuando se prepara el programa, abra el Centro diocesano, escuche los proyectos, los discuta, los coordine y los sintetice con los de otros organismos, para luego dar su aprobación y su aliento concreto, decidiendo incluso en qué puntos del programa va a intervenir él en primera persona.

Todos estamos de acuerdo hoy en pastoral de las vocaciones que una opción no madura simplemente a través de experiencias esporádicas de fe, sino a través de un paciente camino de discernimiento espiritual. Itinerarios que recorran tres momentos: el anuncio, la propuesta y el acompañamiento vocacional ${ }^{12}$. Tengo la convicción de que el obispo está llamado en primera persona a empeñarse en un competente acompañamiento vocacional, a conocer personalmente a los candidatos al sacerdocio, a visitar el seminario, a escoger con especial clarividencia a los responsables vocacionales, incluso con valentía, a los mejores colaboradores que tiene a su disposición para lograr este objetivo.

9. Concilio Vaticano II, Christus Dominus, 15

10. Cf. C. M. Martini, La vocación en la Biblia, Sígueme, Salamanca ${ }^{2} 2013$, 27s.

11. Cf. Conferencia episcopal italiana, Vocazioni nella Chiesa italiana, 54.

12. Cf. ibid. 
e) El sostenimiento permanente que ha de ofrecer al Seminario y, en especial, a la comunidad de los formadores

Para el magisterio de la Iglesia, el obispo es el responsable máximo de la formación de los futuros sacerdotes, y lo exhorta a que considere esta formación como su prioridad ${ }^{13}$. El obispo intenta desarrollar este deber, que es compartido, formando a sus sacerdotes a ejemplo de Jesús, en tres etapas: llamando a los que quiere, estando con ellos y enviándolos al mundo ${ }^{14}$.

Desde que el Concilio de Trento instituyó los seminarios no hay en la Iglesia una alternativa al seminario; de hecho, se recomienda que «el obispo insista decididamente y con convicción sobre la necesidad del seminario mayor como instrumento privilegiado para la formación sacerdotal ${ }^{15}$. Para cumplir su responsabilidad con la formación de los futuros sacerdotes, es ante todo responsabilidad del obispo escoger bien a los formadores y a los profesores. Los criterios en los que ha de basarse la elección están claramente señalados por la Iglesia: «La madurez humana y espiritual, la experiencia pastoral, la competencia profesional, la estabilidad de la propia vocación, la capacidad de colaboración, la preparación doctrinal en las ciencias humanas (especialmente la psicología) correspondiente al oficio, el conocimiento de las formas de colaborar en grupo» ${ }^{16}$. Y señala que dicha elección ha de hacerse teniendo como criterio que sean «los mejores entre los sacerdotes de la diócesis» ${ }^{17}$.

Otra cualidad que deben tener los formadores y profesores del Seminario es la unidad con el obispo. La necesidad de la unidad es útil porque ayuda a la armonía en la formación de los futuros sacerdotes. Y encuentra razón también en el testimonio que los futuros sacerdotes han de dar en la práctica para construir su vida en unidad con el obispo y el presbiterio. Sólo así los futuros sacerdotes tienen garantía de su perseverancia en la vocación y en el cumplimiento de la misión confiada a ellos en la Iglesia estén donde estén.

Esta unidad de los formadores y profesores con el obispo debe ser estimulada ante todo por el mismo obispo ${ }^{18}$. Para lograr esto, el obispo debe primero y personalmente visitar a menudo el corazón de la diócesis y velar por la formación de los alumnos, el proceso formativo y educativo, el crecimiento vocacional de los clérigos, la piedad y sus progresos ${ }^{19}$. En esa visita no debería faltar el encuentro directo e informal con los clérigos para conocerlos personalmente, fomentando el sentimiento de familiaridad y de amistad con ellos. «Esta relación familiar permitirá al obispo poder valorar mejor la idoneidad de

13. Cf. Directorio para el ministerio pastoral de los obispos, 84.

14. Cf. Juan Pablo II, Pastores dabo vobis, 65.

15. Directorio para el ministerio pastoral de los obispos, 85.

16. Juan Pablo II, Pastores dabo vobis, 66.

17. Directorio para el ministerio pastoral de los obispos, 89.

18. Cf. Juan Pablo II, Pastores dabo vobis, 66.

19. Cf. Directorio para el ministerio pastoral de los obispos, 88; CIC $259 \S 2$. 
los candidatos al sacerdocio y comparar su juicio con el de los superiores del seminario, juicio que está en la base de la promoción al sacramento del Orden ${ }^{20}$. En esa visita al Seminario no puede faltar la comprobación de la vida comunitaria por parte del obispo. La práctica ha demostrado que a menudo falta y lamentablemente se descuida. El papa Francisco afirma que la falta de vida comunitaria «favorece un estilo de vida que debilita el desarrollo y la estabilidad de los lazos entre personas $»^{21}$. Los formadores a menudo prestan poco interés en el modo de instruir la relación entre los alumnos. Se interviene sólo cuando aparecen los problemas. Cuando los profesores no tienen una relación adecuada con los seminaristas, se corre el peligro de no ser suficientemente interpelados ni de ayudarles a trabajar con sinceridad y verdad sobre el propio camino. El obispo, cuando mantiene una estrecha relación con los formadores, ha de insistir en prestar especial atención para que traten de conocer la realidad de la vida cotidiana de los alumnos, y esto requiere esfuerzo, trabajo y competencia. Es necesario que el obispo anime a los formadores a actuar más paternalmente que autoritariamente, de modo que los clérigos vean ya en el Seminario un espíritu de confianza solidaria y de unidad en el presbiterio, favoreciendo un verdadero y sano diálogo educativo con los alumnos.

Durante la formación de los seminaristas, los formadores encuentran en el Seminario muchas dificultades y necesitan apoyo y confianza. Cuando el obispo vive las vicisitudes del Seminario visitando y relacionándose con los seminaristas y los formadores, poco a poco llegará a captar el ambiente del Seminario. Esto ayudará a comprobar las aptitudes incluso de los educadores. Se aprecia que a veces los formadores reflexionan poco sobre sus aptitudes y conductas. Si los formadores no llevan una vida madura y piadosa, si no se esfuerzan en cultivar las virtudes y promover el diálogo entre ellos, ¿cómo podrán tener autoridad y ganarse la confianza de los seminaristas? En la comprobación de la actitud de los formadores, el obispo debe participar personalmente, y cuando note la falta de diálogo o situaciones más problemáticas, debe intervenir inmediatamente para remodelar la comunidad educativa.

Otro punto esencial de la colaboración del obispo con los formadores es la toma de decisiones importantes, como la admisión a los ministerios, la designación de las prácticas pastorales, los exámenes, etc. Sabido es que el obispo en cada caso tiene el derecho de decidir y decir la última palabra, pero no puede prescindir de la opinión y valoración de los formadores. Una correcta actitud del obispo refuerza la colaboración entre ellos, genera el mutuo respeto y confirma a los formadores en su competencia. Tal postura del obispo con los formadores puede influir en el buen clima de colaboración recíproca, que a su vez recaerá positivamente en las relaciones con los alumnos. 
Además, hay que recordar que incluso un Seminario bien preparado requiere una constante renovación. El obispo, conociendo la situación desde dentro y leyendo los signos de los tiempos y las necesidades de la Iglesia local, debería llevarla a cabo en caso de necesidad ${ }^{22}$.

\section{f) El cuidado específico de los sacerdotes y de su formación permanente}

Esta preocupación, que ha sido constante en la historia de la Iglesia, se ha acentuado en tiempos recientes, sobre todo a partir del Concilio Vaticano II. No sólo respecto a la formación de los candidatos al presbiterado, sino también a la formación de los presbíteros. La formación permanente se revela cada vez más necesaria, ya sea para mostrar una imagen verdadera y significativa del presbítero, ya sea para garantizar una honda renovación de la Iglesia en una época de grandes cambios. El obispo, que es el padre del presbiterio, debe velar por la continuidad de la formación espiritual e intelectual ${ }^{23}$.

El primer llamado a la formación permanente es el obispo «para que, a través del testimonio de la propia madurez humana, espiritual e intelectual en la caridad pastoral... brille siempre más la caridad de Cristo y la misma solicitud de la Iglesia hacia todos los hombres» ${ }^{24}$.

Entre los medios para la formación permanente, el obispo ha de favorecer el estudio de los documentos doctrinales y pastorales del magisterio pontificio, de la Curia romana, de la Conferencia episcopal y de los obispos hermanos en el episcopado. Así encontrará orientaciones para su actividad pastoral y para iluminar a los fieles en las principales cuestiones que la sociedad actual continuamente presenta. En cualquier caso, conviene no olvidar «que la vida de comunión con los otros miembros del Pueblo de Dios, la vida cotidiana de la Iglesia y el contacto con los presbíteros y los fieles representan siempre momentos en los que el Espíritu habla al obispo, recordándole su vocación y misión y formando su corazón a través de la vida viva de la Iglesia» ${ }^{25}$.

También los presbíteros están llamados por el obispo a una formación permanente. Este proceso formativo es una continua conversión que comporta la dimensión humana, intelectual y pastoral del presbítero. La formación permanente busca «ayudar al sacerdote a ser y a desempeñar su función en el espíritu y según el estilo de Jesús, Buen Pastor... a hacer que el sacerdote sea una persona profundamente creyente y lo sea cada vez más; que pueda verse con los ojos de Cristo» ${ }^{26}$. Las ocasiones concretas que pueden servir de ayuda a la formación permanente son de diverso nivel: espiritual, intelectual y pastoral.

22. Cf. Juan Pablo II, Pastores dabo vobis, 61.

23. Cf. CIC 279.

24. Directorio para el ministerio pastoral de los obispos, 49.

25. Ibid., 54.

26. Juan Pablo II, Pastores dabo vobis, 73. 
A nivel espiritual están los ejercicios espirituales realizados en común entre los presbíteros de la Iglesia particular. Muchas diócesis ofrecen varios turnos de ejercicios, para promover la participación. La presencia del obispo diocesano se considera muy positivamente, incluso para favorecer los encuentros con cada sacerdote. Otra práctica muy generalizada son los retiros espirituales mensuales. Analizando la necesidad de una formación permanente y completa en cada fase de la vida sacerdotal, me atrevo a referirme a la situación de la Iglesia en Bielorrusia, donde la necesidad de formación permanente del clero hoy está condicionada no sólo por la situación histórica de los tiempos del ateísmo, sino sobre todo por la diversidad del clero. Tras un periodo de persecución, cuando la Iglesia en nuestra tierra ha recuperado su libertad y ha comenzado a crecer en todo el país, naturalmente ha llegado la necesidad de tener sacerdotes. Hemos hecho frente a este problema de distintas maneras. Hemos descubierto que una parte del clero se formó en secreto y fue ordenada por los distintos obispos que podían encontrarse en aquellos tiempos. Algunos sacerdotes se formaron fuera de Bielorrusia y adquirieron cierta formación. Para ayudar a nuestra Iglesia en esta dificultad, gran parte del clero ha venido de fuera y su contribución ha sido fundamental. En la práctica pastoral y en la vida del presbiterio, sin embargo, estas diferencias en la formación -a mi modesto entender- no siempre han tenido un papel positivo, sobre todo en la colaboración entre sacerdotes, así como en la pastoral con la gente. Nuestros obispos viendo esto, han organizado encuentros mensuales en cada diócesis con todos los presbíteros, religiosos y religiosas para favorecer una formación permanente unificada en la Iglesia particular. El obispo elige los temas más adecuados para cada encuentro, que comienza con la oración y la meditación del padre espiritual de la diócesis, seguida de la exposición del Santísimo Sacramento y la posibilidad de reflexionar, adorar y confesarse. Tras la celebración de la eucaristía presidida por el obispo, vienen las preguntas, comentarios y un ágape fraterno. Ahora se ve que este tipo de formación permanente del presbiterio en la diócesis ayuda a afinar algunos aspectos débiles de la vida y de nuestro servicio a los fieles, y por parte del obispo esto ayuda a un acercamiento eclesial más maduro.

Otro nivel de la formación permanente de los presbíteros es el intelectual. En no pocas diócesis son obligatorios, o casi obligatorios, los cursos de actualización para los sacerdotes. Esto favorece el repaso de temas teológicos fundamentales y al mismo tiempo la fraternidad entre presbíteros. Casi siempre durante estos cursos está previsto el encuentro con el obispo o incluso su participación prolongada en él.

Otra iniciativa es la de las jornadas teológicas de actualización al compás del año litúrgico-pastoral: son cursos programados ya en alguna Iglesia y se ve que hace falta mayor difusión. La metodología trata de conseguir que los 
participantes no se limiten sólo a escuchar, para trabajar activamente a través de una adecuada preparación e incluso a través de un compromiso activo durante la celebración de las jornadas.

Otro nivel de la formación permanente de los presbíteros es el pastoral. La experiencia más común en este campo consiste en dos o tres días del clero como profundización en el plan pastoral de la diócesis o los grandes temas de actualidad pastoral. Encuentros para los presbiteros jóvenes en los primeros años de sacerdocio en los que está previsto orar juntos, profundizar en un tema concreto y revisar fraternamente aspectos concretos del ministerio pastoral.

En las diócesis medianas se considera útil la semana para los nuevos párrocos, con la idea de que el sacerdote se inserte como guía de una comunidad, en un ministerio de múltiples dimensiones y competencias, que van desde las problemáticas propiamente pastorales a las jurídicas y administrativas. Hay algunos momentos que están adquiriendo un gran valor simbólico de cara a la promoción de la comunión presbiteral. En especial, la celebración de la misa crismal del Jueves santo, tal vez el momento más fuerte de reunión del presbiterio diocesano en torno al propio obispo.

Otro momento bastante significativo para el presbiterio es la jornada de fraternidad sacerdotal diocesana, habitualmente celebrada en el Seminario, además con la presencia y la animación de los mismos seminaristas. En este contexto de compartir gozoso recordamos los distintos aniversarios de ordenación sacerdotal. En todas las diócesis, este día coincide con el rito de admisión de los seminaristas a las Órdenes. Otro momento muy alentador entre los presbíteros es su numerosa presencia en las ordenaciones de diáconos y de presbíteros. En alguna diócesis estos momentos son escasos, hasta el punto de que cuando se dan constituyen toda una noticia. Pero siempre tienen la fuerza de signo y de esperanza, tanto para el presbiterio como para las comunidades cristianas, que participan frecuentemente con una gran presencia de jóvenes.

Al margen de la diversa tipología que se configura en la intimidad de las vivencias concretas de nuestras Iglesias, se da un elemento común: la exigencia de compartir la fatiga del ministerio en un contexto de complejidad cultural. Precisamente, sobre dichas perspectivas pastorales no pocos presbíteros esperan una palabra de ánimo del obispo y una oportuna reflexión en torno a las cambiantes condiciones del ministerio. Otra experiencia de notable valor formativo es la de los viajes de formación, sobre todo a lugares sagrados o de gran interés pastoral.

Para terminar este apartado me gustaría poner el acento sobre el hecho que el adjetivo permanente, relativo a la formación sacerdotal, está estrechamente unido al carisma del ministerio sacerdotal, que en sí es permanente e irreversible. Justamente por esto, la formación nunca puede considerarse 
completa ni en la Iglesia ni en el sacerdote. Así pues, es necesario que se programe y se desarrolle de forma que todos los sacerdotes la reciban con gusto y que se extienda a lo largo de la vida del pastor ${ }^{27}$.

\section{EL PRESBíteRO, PASTOR DE LAS VOCACIONES}

Amenudo se oye decir que las vocaciones son pocas, que hay necesidad de sacerdotes porque ya existen parroquias sin pastor. Es necesario entonces un esfuerzo de todos los cristianos para que el tema de las vocaciones se coloque en el sitio justo y se refiera a la familia, a la parroquia, a las asociaciones, etc. Si los obispos tienen el deber prioritario de promover la pastoral vocacional, también los presbíteros, en cuanto pastores y más estrechos colaboradores de los obispos, han de estar más comprometidos que los demás. El sacerdote es siempre un promotor vocacional, y su coraje fiel en el cumplimiento de su misma misión es la llave que hace eficaz la pastoral. El sacerdote no puede llamar a nadie si su vida no es concreta respuesta a la llamada de Cristo en la Iglesia. Si el campo privilegiado es el testimonio personal del sacerdote, a nivel de actitudes personales es importante que los sacerdotes puedan vencer los miedos o los apegos que son estorbos, para poder presentar con naturalidad y alegría la fascinación radical de la vocación sacerdotal.

\section{a) La formación de las familias}

El recorrido formativo comienza ciertamente en la raíz, desde la formación de las familias, lugar primero y más importante de crecimiento de las vocaciones. De la familia depende la actitud de los niños y de los jóvenes hacia Dios y los hombres, hacia la vida y hacia uno mismo. En ella se descubre que se es llamado a amar fiel e irrevocablemente, independientemente del hecho de ser llamado a una forma de vida secular o religiosa ${ }^{28}$. Orientadoras en este sentido son las palabras del papa Juan XXIII dirigidas a los laicos en una audiencia: «Dadme familias santas y os daré sacerdotes santos». Por esto, si se quiere cuidar el desarrollo de las vocaciones, es necesario que los sacerdotes presten particular atención a la pastoral de la familia. De hecho, el cuidado de las vocaciones presupone una válida pastoral familiar para ayudarla a que llegue "a ser auténtica», a desarrollar a fondo el propio deber dentro de la única Iglesia, para que florezcan las vocaciones de especial consagración. Se puede constatar que detrás de la crisis de vocaciones hay también una crisis de la familia cristiana: superar la una es condición necesaria para superar la otra. Por eso, ayudar y evangelizar a las familias, sin limitarse sólo a

27. Cf. Directorio para el ministerio y la vida de los presbíteros, 91.

28. Cf. Juan Pablo II, Familiaris consortio, 53. 
algunos preceptos, favoreciendo el encuentro de las personas y caminos de fe y maduración, es un camino que pone las bases para el florecimiento de nuevas vocaciones, incluso sacerdotales.

\section{b) Asegurar la catequesis y la educación de los niños y los adolescentes}

La difusión de una mentalidad post-moderna, secularizada, epidérmica y banal desanima la respuesta de los jóvenes a la invitación de seguir a Jesús con radicalidad y generosidad. Por esto necesitamos asegurar el servicio de la catequesis y de la educación de los niños y adolescentes. En la educación de la fe de los niños y adolescentes nunca debería faltar un verdadero y preciso itinerario espiritual. Es importante no sobreponer la dimensión vocacional como si fuese un tema más, sino hacer que emerja desde dentro, de manera casi natural, en las distintas unidades didácticas previstas en los catecismos y sobre todo en la experiencia del encuentro con el Señor. No en vano, catequesis y vocación son dos realidades que se encuentran la una al servicio de la otra. Toda catequesis vocacional será infructuosa si falta el testimonio de vida de los catequistas y de los sacerdotes. Por eso es oportuno recordar las hermosas palabras del beato Pablo VI: «El hombre contemporáneo escucha mucho mejor los testimonios que a los maestros, o si escucha a los maestros lo hace porque son testigos ${ }^{29}$. Lo que significa que una enseñanza separada del testimonio personal difícilmente comportará un efecto vocacional. Pienso que hoy hemos de volver con valentía a presentar la propuesta de las diversas vocaciones; más aún, hemos de encontrar su momento adecuado dentro del itinerario catequético y comunitario. Esta propuesta supone un conocimiento de las diversas vocaciones y una colaboración eventual de los animadores que han realizado diversas opciones de vida; de esta forma, podrán testimoniar en el itinerario catequético y educativo una experiencia que invite a imaginar y plantear la propia vida, para descubrir así con la ayuda eclesial el germen de la propia vocación.

\section{c) El sacerdote, una referencia para los seminaristas}

Para ser una sólida referencia de imitación para los seminaristas, hay que recordar antes qué y quién es el sacerdote. Al respecto no tengo una respuesta clara e inequívoca, pues el sacerdocio adquiere densidad a través de las diversas fases de la vida. Recuerdo que mientras terminaba los estudios superiores, al volver de la experiencia de dos meses en el noviciado salesiano durante las vacaciones, por consejo del maestro de novicios, busqué al confesor que me había acompañado durante los años anteriores a mi ingreso

29. Discurso a los miembros del Consilium pro laicis, Roma, 2 de septiembre de 1974. 
en el noviciado. Al relacionarme con distintos sacerdotes, me di cuenta de que el sacerdote no puede ser sustituido por cualquiera. Sólo el sacerdote, si vive plena y auténticamente el propio sacerdocio, recibe la gracia de acercar al hombre a Dios de un modo particular.

Leyendo y oyendo muchas historias de diversas vocaciones sacerdotales, estoy convencido de que ellas no dependen tanto de propuestas teológicas o de altísima espiritualidad, mucho menos de las capacidades humanas o de la eficacia organizadora de las estructuras eclesiales, que pueden ayudar, orientar e inspirar, como de la mediación personal de alguien que es un referente claro y fuerte. Permítanme, una vez más, recurrir a la experiencia personal. Cuando en el año 1989, en mi ciudad de nacimiento Smarhon, las personas ancianas obtuvieron el permiso para recuperar su iglesia, que durante mucho tiempo se había convertido en museo del ateísmo, el gobierno puso una condición: si no se llena la iglesia en la primera misa celebrada allí, de nuevo se convertiría en museo del ateísmo. Mi párroco, don Henryk Kulaszewicz, estaba muy preocupado por el número de personas que asistirían. Llegado el domingo, a la primera misa vino tanta gente que no cabían en la iglesia, y hasta la plaza y el parque estaban llenos de fieles. Al final, durante la procesión eucarística de acción de gracias se pasó muy cerca de la estatua de Lenin, que miraba desde la plaza principal hacia la iglesia. Mi párroco, apretando el Santísimo dijo entre lágrimas: «Lenin, toda tu vida luchaste contra la fe y querías destruir la Iglesia, matándola en el corazón de la gente; mira cuánta gente ha venido, acuérdate de que Dios es más fuerte que tú y que tus ideas». No sólo sus ideas, sino también las nuestras: la vida personal, el encuentro con el Señor de la comunidad, la experiencia directa y personal del Señor sigue siendo un camino insustituible para reunir el pueblo santo de Dios y permitir a Dios que llame a los pastores para su pueblo.

De niño vi en mi párroco un hombre que amaba al Señor y le servía con dedicación y celo sacerdotal enormes. Vi que su fuente era la eucaristía, su medio de practicar la oración personal. Vi a un hombre entregado a los hombres, especialmente a los jóvenes, que con sacrificio y gozosa dedicación servía al Señor y amaba sinceramente a la gente. En esto se basaban sus enseñanzas y su predicación. Viendo todo esto yo también empecé a querer ser como él, salesiano y sacerdote, padre de la comunidad que se llama parroquia, predicador y testigo de la palabra de Dios, servidor de los jóvenes, especialmente de los más pobres. Su apoyo en el camino vocacional no terminó con mi ingreso en el noviciado, sino que continuó con cierta intensidad durante todo el periodo de formación. Todavía ahora, a sus 87 años, sigue siendo una referencia para mi ministerio episcopal. El auténtico testimonio de un sacerdote, la fidelidad a su vocación, su celo apostólico y un continuo acompañamiento en el Seminario pueden ayudar a perseverar y hasta salvar la vocación en los momentos de dificultad que no faltan, de inseguridad y de 
tentación. Esos momentos no se pueden evitar, pero junto a un acompañamiento ininterrumpido sirven para crear y alimentar una actitud de fidelidad a la propia vocación.

\section{d) El sacerdote, servidor de la dirección espiritual}

En el apartado anterior he tratado de mostrar la importancia del testimonio personal y de la constante preocupación por los seminaristas de parte de los sacerdotes. Ahora quiero recordar que la forma privilegiada de discernimiento y de acompañamiento vocacional es la dirección espiritual: que es donde el sacerdote pone en práctica su paternidad espiritual ${ }^{30}$. Hay que reconocer que la dirección espiritual hoy está en crisis. Muchos sacerdotes, que durante el seminario y en los primeros años de sacerdocio han tenido el propio padre espiritual y han acudido a él para confesarse, aconsejarse y recibir ayuda en las dificultades, han dejado de frecuentarlo. Bastante laicos, que desean recibir una dirección espiritual al margen de la confesión, no encuentran sacerdotes y religiosos dispuestos a ayudarles.

Por otra parte, es necesario suscitar en los adolescentes y en los jóvenes el deseo de la dirección espiritual personal como instrumento de crecimiento en la fe y de educación a una vida cristiana más auténtica y más personal ${ }^{31}$. Frente a la crisis de dirección espiritual, es curioso el recurso cada vez mayor a psiquiatras, psicoanalistas, psicoterapeutas, en los casos de molestias no psíquicas, simplemente para tener una ayuda psicológica. En el mundo juvenil se nota que se recurre con frecuencia a la guía de un gurú del yoga o del zen para introducirse y ser guiados en la búsqueda espiritual. Se trata de fenómenos que de entrada no tienen que ser condenados, pero habría que vigilar en nosotros lo específico de nuestro acompañamiento, el de la vida según el Espíritu, con las riquezas interiores que ninguna otra tradición probablemente es capaz de ofrecer. Esta búsqueda es también un signo de los tiempos en los que ha venido a menos la Iglesia, por lo que se busca fuera y a menudo, lamentablemente, de manera inadecuada ${ }^{32}$.

Estoy seguro de que el primer paso para recuperar una ardiente vida pastoral está en la sensibilidad de los sacerdotes a prestar ayuda en los problemas humanos y espirituales. El obstáculo para esto probablemente haya que buscarlo, en primer lugar, en la falta de pastores preparados para este tipo de ministerio. Lo que desanima es una actitud errada, paternalista y moralizante. Hay que educar a nuestros seminaristas y sacerdotes jóvenes

30. Cf. Papa Francisco, Discorso ai seminaristi, ai novizi e alle novizie provenienti da varie parti del mondo in occasione dell'Anno della Fede, Roma, 6 de julio de 2013.

31. Cf. M. Giordano, Omelia durante il Mercoledi delle Ceneri, Nápoles, 13 de febrero de 1991.

32. Cf. Ibid. 
en la convicción de que nadie se convierte en un buen director espiritual por el hecho de haber recibido la ordenación.

No cabe duda de que el carisma de guía espiritual está presente en la gracia del sacerdocio, pero nace poco a poco a través de la profundización de la vida espiritual y el discernimiento en el diálogo de la dirección espiritual, a través de un paciente y constante trabajo interior. El sacerdote llega a ser director si, antes de nada, recurre él mismo a los medios y las reglas de una seria dirección espiritual.

Por lo que respecta a la dirección espiritual, en los sacerdotes se requiere una consciente disponibilidad de escucha y diálogo, de comprensión y apertura, superando toda forma de rigidez hacia los otros y hacia uno mismo. La competencia esencial del sacerdote como director espiritual es el conocimiento experimentado de las fases de la vida espiritual. Un buen director espiritual tendría que ser emotivamente equilibrado, constante en la meditación diaria y en la dirección espiritual. La gente se da cuenta y lo evita si, por ejemplo, no le ve nunca rezando. Se puede constatar que, donde existe la práctica de la dirección espiritual, se da una renovación personal y comunitaria, surgen vocaciones y crece el espíritu apostólico.

\section{e) El sacerdote, alegre testigo de la propia vocación}

La misión cristiana está dirigida a todos y nadie queda excluido. «Un buen pastor, un pastor según el corazón de Dios, es el mayor tesoro que nuestro Señor puede conceder a una parroquia y uno de los más preciados dones de la misericordia divina» ${ }^{33}$. En la enseñanza y en las diversas ocasiones del encuentro del papa Francisco con los sacerdotes se repite que el mundo necesita testigos, especialmente testigos gozosos de Cristo.

¿Cuál es el secreto para estar contentos de la vocación sacerdotal? Cuatro palabras: oración, para encontrar y conocer cada día más a Jesús, alimentando el fuego recibido; formación, para dar razón de la esperanza que hay en nosotros y tratar de cumplir bien; comunidad, porque Jesús envió a los apóstoles de dos en dos y «eligió a doce a quienes dio el nombre de apóstoles» (Lc 6, 13); misión, para llevar el Evangelio a donde vive la gente: escuelas, calles, playas, centros comerciales, discotecas, cárceles, hospitales, etc., donde quiera que haya personas que todavía no han encontrado el amor de Dios.

Además, recuérdese que la palabra sacerdos evoca dar lo sacrum, entregar algo que remite a lo Santo, a la santidad. Todo lo demás lo puede dar el mundo. La santidad, la espiritualidad, es prerrogativa que no conoce sucedáneos y que el sacerdote nunca debe permitirse sustituir por otra cosa.

33. B. Nodet, Le Curé d'Ars: sa pensée, son coeur, 101. 
Existe otra palabra que conviene recordar: pontifex, que significa artífice de un puente entre el momento presente y la eternidad, entre el cielo y la tierra. Hemos de recordar que el puente se construye para que otros puedan pasar por él. La mayor parte de las personas pisa el puente: por una parte duele, pero por otra suscita alegría y felicidad. Ese es el misterio de la vida dada, de la vida no vivida ya para sí mismo; la vida de pastor que señala al Pastor, fuente de la «caridad pastoral».

Para ser testigo alegre un sacerdote tiene que empeñarse y motivarse seriamente en la vocación cada día de su vida. Nuestra vida debería llegar a ser un lugar santo en el que madurar la conciencia de que no desarrollamos una profesión, aunque hermosa y útil, sino que vivimos con gozo un misterio de amor oblativo recibido de Dios y dado a Él y a los hermanos. Además, para ser testigos felices no hemos de engañarnos valorando la eficacia de la gracia de Dios según las estadísticas de la práctica religiosa, sino avanzando con mayor profundidad a fin de madurar una mirada auténticamente espiritual, que sabe leer las vivencias y la historia con la óptica del Crucificado Resucitado. La verdadera conversión del corazón y el cambio de actitud sacerdotal son capaces de rehacer el gozo de ser los sacerdotes alegres de Cristo Jesús, llamados a una altísima y única responsabilidad.

FINAL

Me gustaría concluir con un deseo: que todos nosotros, pastores en y para nuestra Iglesia, llamados a caminar bajo la mirada maternal de María y siguiendo la guía profética de Pedro hoy, el papa Francisco, descubramos la belleza de nuestra responsabilidad, que reside en el plan de Jesús, y la valentía de avanzar cumpliendo lo mejor posible nuestros deberes de pastores, llamados a llamar. Que recordemos, en fin, que lo importante no es cuántos seremos, sino si somos ya lo que sabemos que debemos ser. 